\title{
Caracterización química y nutrimental de variedades de maíz (Zea mays L.) de alta calidad de proteína (QPM) desarrolladas en Yucatán, México
}

\author{
Chemical and nutritional characterization of high quality protein maize (Zea mays L.) varieties \\ developed in Yucatan, México
}

\begin{abstract}
Manuel Chan-Chana, Yolanda Moguel-Ordóñez ${ }^{b}$, Santiago Gallegos-Tintoréa, Luis Chel-Guerreroa , David BetancurAncona $^{\mathrm{a} *}$

a Facultad de Ingeniería Química. Universidad Autónoma de Yucatán. Periférico Norte Km. 33.5, Tablaje Catastral 13615, Colonia Chuburná de Hidalgo Inn, 97203, Yucatán, México.

b Campo Experimental Mocochá, Instituto Nacional de Investigaciones Forestales, Agrícolas y Pecuarias. Campo experimental Mocochá, C.P. 97454.Yucatán, México.
\end{abstract}

\section{RESUMEN}

La desnutrición es un problema que afecta a las comunidades rurales. El maíz es alimento básico cuya ingesta es esencial para el crecimiento y desarrollo de los infantes. La calidad proteínica del maíz es pobre debido a la deficiencia de aminoácidos como lisina y triptófano, por lo cual, se han desarrollado maíces de calidad de proteína (denominados QPM). Por lo que en el presente estudio, se realizó la caracterización química y nutrimental de los granos de maíz híbrido Sac Béh y Chichén Itzá, determinando la composición químico proximal, los minerales $\mathrm{Ca}, \mathrm{Fe}, \mathrm{K}, \mathrm{Mg}$, Na y P; el perfil de ácidos grasos y de aminoácidos. Se evaluó la calidad de la proteína mediante la digestibilidad "in vitro" y cómputo químico, aminoácido limitante, la puntuación de aminoácidos corregido con digestibilidad de proteínas (PDCAAS), la relación de eficiencia de proteína calculada (c-PER) y el valor biológico (VB). Se demostró un aumento de proteínas y alto contenido de aceite con $7 \%$ de lípidos. Se encontró un mayor contenido de ácidos grasos monoinsaturados (MUFA) que saturados (SFA) y se mantuvo el contenido mineral. La calidad de la proteína fue superior con respecto a los predecesores, con mayores niveles de lisina, triptófano, fenilalanina e isoleucina, mayor digestibilidad y el doble de valor biológico.

Palabras clave: Maíz, híbridos, valor nutrimental, calidad de proteína, minerales

\section{ABSTRACT}

Malnutrition is a problem that affects rural communities worldwide. Maize is a food whose intake and nutritional quality is essential for the growth and development of infants. Maize protein quality is poor due to amino acid deficiencies such as lysine and tryptophan, which has generated the development of the so-called quality protein maize (QPM). Chemical and nutritional characterization of the Sac Béh and Chichén Itzá maize hybrids was performed. The proximal analysis, minerals $\mathrm{Ca}, \mathrm{Fe}, \mathrm{K}, \mathrm{Mg}, \mathrm{Na}$ and $\mathrm{P}$, fatty acid and amino acid profiles were determined. Protein quality was also evaluated by the determination of in vitro digestibility and chemical score, limiting amino acid, protein digestibility-

\footnotetext{
*Autor para correspondencia: David Betancur Ancona

Correo electrónico: bancona@correo.uady.mx

Recibido: 22 de julio de 2020

Aceptado: 16 de noviembre de 2020
}

corrected amino acid score (PDCAAS), calculated protein efficiency ratio (c-PER), and the biological value (BV). In hybrid varieties, an increase in protein was demonstrated. They were high oil corn (HOC) with $7 \%$ lipids. A higher content of monounsaturated fatty acids (MUFA) than saturated fatty acids (SFA) was found with an improvement in the quality of the oil, and the mineral content maintained. The protein quality was superior with respect to the native predecessors, with higher levels of lysine, tryptophan, phenylalanine and isoleucine, with greater digestibility and with double biological value.

Keywords: maize; hybrids; nutritional value; protein quality; minerals

\section{INTRODUCCIÓN}

El maíz (Zea mays L.) es una de las fuentes de alimento más importantes del mundo consumidas por humanos y animales, ya que aporta alrededor del 50 \% de la proteína y varios nutrimentos que complementan la dieta habitual, como minerales, fibra dietética y grasas insaturadas. Sin embargo, el maíz tiene algunas limitaciones, como baja calidad de su proteína (Li y Vassal, 2016). Se considera que sus proteínas se encuentran desequilibradas nutricionalmente ya que las zeínas, sus proteínas de almacenamiento más abundantes, no poseen las cantidades suficientes de aminoácidos esenciales como lisina, triptófano y metionina (Gayral et al., 2016). La desnutrición infantil es uno de los problemas que afectan a la población debido a la falta de proteína de calidad en la alimentación e inaccesibilidad a alimentos con alto valor nutritivo; principalmente por parte del sector de la población con un nivel socioeconómico bajo, situación que ha ocasionado problemas en el desarrollo de los infantes (Salazar y Magaña, 2016).

La deficiencia de aminoácidos esenciales en el maíz ha llevado a dos estrategias para subsanarla. La primera consiste en incorporar en los productos hechos de maíz, como la tortilla, proteínas cuya composición de aminoácidos sea complementaria, como por ejemplo la proteína de leguminosas. La segunda consiste en suplementar dichos produc- 
tos con L-aminoácidos libres como lisina y triptófano en las concentraciones requeridas (Akalu et al., 2010). De optarse por la primera opción, debe considerarse que las características sensoriales cambian con la adición de otra fuente de proteína. Con la segunda alternativa será necesario controlar la adición aminoácidos debido a que, una suplementación excesiva puede producir producir efectos tóxicos o antagonismo aminoacídico.

Durante la década de 1960 y 1970, fueron identificadas mutaciones naturales de genes de maíz, como opaco-2 (o2), fluory-2 (fl2), opaco-7 (o7), opaco-6 (o6) y fluory-3 (fl3) que generan variedades con mayores niveles de lisina y triptofano. El gen opaco-2 fue llamado así, porque confiere a los granos una apariencia opaca y amilácea. El genotipo original del maíz portador del gen o2 está asociado con bajo rendimiento de granos, endospermo blando y calcáreo, alta susceptibilidad a la ruptura y daños causados por plagas y hongos. El maíz opaco-2 posee el gen mutante recesivo (o2), que limita la síntesis de zeína y aumenta el contenido de las otras fracciones proteicas como las albúminas y las globulinas. Como resultado, se genera una matriz proteica con diferente distribución de aminoácidos y la duplicación del contenido de Lis y Trp. De esta manera, la expresión de este gen permite que el valor nutricional de este maíz sea superior al maíz normal (Hasjim et al., 2009).

La incorporación de este gen en las variedades maíz se puede lograr mediante cruzas y retrocruzas dando lugar a nuevas variedades de maíz que poseen cantidades superiores de lisina y triptófano (Tang et al., 2013). Se han realizado investigaciones interdisciplinarias a través de programas de mejoramiento de maíces convencionales aceptables agronómicamente y nutricionalmente mejorados Ilamados "Maíz de Alta Calidad de Proteína" (Quality Protein Maize, QPM, por sus siglas en inglés). Los QPM se desarrollaron para las regiones donde el maíz forma parte de la canasta básica de alimentos, y diversos estudios han indicado que dichos maíces han tenido impacto positivo en el aumento de peso de aves y cerdos (Tiwari et al., 2013). En los últimos años el Instituto Nacional de Investigaciones Forestales, Agrícolas y Pecuarias (INIFAP) ha desarrollado en diferentes regiones de México, semillas de alta calidad genética, fisiológica, sanitaria y física, en combinación con un alto rendimiento y por consecuencia mayor rentabilidad en el proceso de multiplicación de simientes. En especial, han sido dirigidos hacia las áreas marginales del Sureste de México, principalmente, para generar materiales que atiendan el problema de la desnutrición. Entre éstas variedades desarrolladas se encuentran el Sac Béh (maíz blanco) y Chichén Itzá (maíz amarillo), las cuales tienen un 75 $\%$ de germoplasma criollo y un $25 \%$ del donador de calidad proteínica. También, son de ciclo intermedio tardío, poseen características innatas de los maíces criollos, como su adaptación a las condiciones del sistema roza-tumba-quema o milpa; asimismo, pretenden ser una opción más para mejorar la producción de los campesinos, coadyuvar a satisfacer el requerimiento de maíz anual y mejorar el nivel de vida de las familias (Aguilar-Castillo et al., 2010). Sin embargo, aunque estas variedades cuentan con características como resistencia a plagas, estrés hídrico y buen desarrollo durante la siembra, mismas que favorecen su uso en el sector agrícola, no se habían caracterizado en cuanto a sus propiedades fisicoquímicas y a su valor nutrimental. Dicha caracterización es importante debido a que fueron desarrollados para consumo humano con el objetivo de aminorar el efecto de la desnutrición en aquellas zonas de la población donde aún se cultiva el maíz para autoconsumo y que dependen mayormente de este alimento. Por lo anterior, el objetivo del presente trabajo fue caracterizar química y nutrimentalmente las dos variedades de maíz híbrido Sac Béh y Chichén Itzá desarrollados en el sureste de México.

\section{MATERIALES Y MÉTODOS \\ Granos y harinas}

Se utilizaron granos de maíz QPM de las variedades híbridas Sac Béh, Chichén Itzá y dos variedades control, que consistieron en los predecesores nativos de cada variedad, respectivamente, las cuales fueron proporcionadas por el Instituto Nacional de Investigaciones Forestales Agrícolas y Pecuarias (INIFAP), y cosechadas en Yucatán, México. La caracterización química y nutrimental de las variedades, se realizó a partir de la harina por lo que previamente previamente se llevó a cabo la molienda de los granos. Primero en un molino manual para granos y posteriormente en un molino de impacto ciclónico Cyclotec 1093 Foss (Tecator, Sweeden) para obtener una harina más fina (malla 60, 250 $\mu \mathrm{m})$. Finalmente, las harinas obtenidas se almacenaron a -10 ${ }^{\circ} \mathrm{C}$ hasta la evaluación.

\section{Composición química proximal}

La composición proximal de las harinas de maíz QPM y sus predecesores, fue determinada mediante las metodologías propuestas por la AOAC (2012). La humedad (método 925.10) consistió en el secado de $2 \mathrm{~g}$ de muestra en estufa a $110{ }^{\circ} \mathrm{C}$ hasta lograr peso constante. Las cenizas (método 923.03) consistió en la incineración de 3-5 g de muestra en una mufla a $550^{\circ} \mathrm{C}$. La grasa cruda (método 2003.06) consistió en la extracción de materia soluble en hexano utilizando un equipo Soxtec (Tecator, Sweeden). El nitrógeno (método 2001.11) se realizó de acuerdo con el método Kjeldahl, usando cobre como catalizador usando el sistema Kjeltec (Tecator, Sweeden). La proteína cruda se expresó con un factor de conversión de nitrógeno a proteína de 6.25. La fibra cruda (método 962.09) se determinó como el residuo orgánico combustible e insoluble después de una digestión ácida y alcalina utilizando un equipo Fibertec (Tecator, Sweeden). Los carbohidratos totales fueron estimados como extracto libre de nitrógeno (ELN) restando a 100 los porcentajes de humedad, ceniza, grasa cruda, proteína cruda y fibra cruda.

\section{Cuantificación de minerales: $\mathrm{Ca}$, Fe, $\mathrm{K}, \mathrm{Mg}, \mathrm{Na}$, P}

Para la determinación de minerales de las harinas de maíz QPM y sus predecesores, se empleó el método 985.01 de la AOAC (2012) por medio de espectroscopia de emisión 
atómica con adaptación de plasma inductivamente acoplado a plasma de microondas (Agilent Technologies, CA, USA). Las muestras se analizaron en el espectrofotómetro con las condiciones específicas para cada elemento: Longitud de onda (nm): Ca, 393.37; Fe, 371.99; K, 766.49; Mg, 285.21; Na, 588.99; $\mathrm{P}, 213.62$; considerando un rango de flujo del nebulizador de 0.9-1.9 L/min, un tiempo de lectura de $3 \mathrm{~s}$, tiempo de estabilización de $15 \mathrm{~s}$, una velocidad de la bomba de $15 \mathrm{rpm}$ y se realizaron tres réplicas por muestra. La cuantificación de los minerales se realizó por el método de estándar externo mediante el uso de curvas de calibración a las concentraciones de $0,0.5,1,3,5,7,10,13,15$ ppm para cada elemento, para ello se empleó una solución intermedia de 50 ppm que fue elaborada a partir de una solución madre de 500 ppm.

\section{Perfil de ácidos grasos}

El perfil de ácidos grasos de las harinas de maíz QPM y sus predecesores, se determinó de acuerdo con el método 996.06 de la AOAC (2012) por cromatografía de gases capilar posterior a la formación de los ésteres metílicos de los ácidos grasos (FAMEs) usando trifluoruro de boro en metanol. Se utilizó un equipo Agilent Technologies (modelo 7890A, CA, USA), se empleó un inyector Split a una temperatura de 225 ${ }^{\circ} \mathrm{C}$, el detector a $285^{\circ} \mathrm{C}$ y la columna SP2560 a temperatura inicial de $100^{\circ} \mathrm{C}$, usando una rampa de $3^{\circ} \mathrm{C} / \mathrm{min}$ hasta llegar a una temperatura final de $240{ }^{\circ} \mathrm{C}$, donde se mantuvo por 15 $\mathrm{min}$. Se utilizó helio como gas acarreador a una velocidad de flujo $0.75 \mathrm{~mL} / \mathrm{min}$, velocidad lineal $18 \mathrm{~cm} / \mathrm{s}$ y como detector el espectrómetro de masas. Para la identificación de los ácidos grasos en la muestra se empleó el espectro de masas de cada componente eluido y se comparó con el de la biblioteca de espectros del National Institute of Standards and Technology (NIST). Los ácidos grasos se cuantificaron en función del área del pico por el método de normalización del área.

\section{Perfil de aminoácidos}

El perfil de aminoácidos de las harinas de maíz QPM y sus predecesores, se determinó a través del método propuesto por Alaíz et al. (1992) por cromatografía de líquidos de alta eficacia (HPLC) en fase reversa en un equipo Agilent (Santa Clara CA, USA). Posterior a la derivatización con etoximetilenomalonato de dietilo, a excepción del triptófano que se realizó con tratamiento alcalino y sin derivatización. Los aminoácidos se separaron usando una columna Nova Pack C18 $4 \mu \mathrm{m}$ de $300 \mathrm{~mm} \times 3.9 \mathrm{~mm}$ D.I. y un gradiente binario de una solución $25 \mathrm{mM}$ de acetato de sodio con $0.02 \%$ de azida de sodio ajustado a $\mathrm{pH} 6$ (solvente A) y acetonitrilo grado HPLC (solvente B) con un flujo de $0.9 \mathrm{~mL} / \mathrm{min}$ con el detector UV-Vis a una longitud de onda de $280 \mathrm{~nm}$ y a una temperatura de $18^{\circ} \mathrm{C}$. La determinación del triptófano se realizó de acuerdo con Yust et al. (2004). La cuantificación de los aminoácidos se realizó por el método del estándar interno mediante el uso de curvas de calibración.

\section{Calidad de la proteína}

Se evaluó la calidad de proteína de las harinas de maíz QPM y sus predecesores por medio de la digestibilidad in vitro, usando el sistema enzimático tripsina-quimotripsinapeptidasa. Luego considerando el perfil de aminoácidos se obtuvieron parámetros de interés como el cómputo químico, el aminoácido limitante, PDCAAS, C-PER y el VB estimado de la proteína.

Digestibilidad in vitro de la proteína. La digestibilidad de la proteína se evaluó por el método propuesto por Hsu et al. (1977) por medio del sistema enzimático tripsina porcina (tipo IX Sigma T-0134 con 14.190 unidades BAEE/ mg de proteína), a-quimotripsina (tipo II Sigma C-4129 con 60 unidades /mg de polvo) y peptidasa (grado III Sigma P-75000 con 40 unidades / $g$ de polvo). Se evaluó la actividad usando caseína como referencia.

Puntaje químico y aminoácido limitante. Se calculó de acuerdo con lo propuesto por Friedman (1996) en donde el puntaje químico se obtuvo como el cociente del contenido de cada aminoácido indispensable de la proteína de prueba, entre el contenido del mismo aminoácido en un patrón de referencia establecido por FAO/FINUT (2017). El aminoácido limitante fue el aminoácido esencial en la proteína de estudio, que mostró la mayor diferencia en la concentración del mismo aminoácido en la referencia.

Puntuación de Aminoácidos Corregida con Digestibilidad de Proteínas (PDCAAS). El PDCAAS se calculó como describe Schaasrfma (2005) según la siguiente fórmula: PDCAAS (\%)

$=\frac{m g \text { del primer aminoácido limitante en } 1 \mathrm{~g} \text { de proteína de muestra }}{m g \text { de del mismo aminestibilidad (\%) }} \times$ EC. 1

Relación de eficiencia de proteína calculada. Los valores de c-PER fueron calculados utilizando la composición de aminoácidos y las ecuaciones desarrolladas por Lee et al. (1978):

$$
\begin{aligned}
& P E R_{7}=0.08084\left[X_{7}\right]-0.1094 \\
& P E R_{10}=0.06320\left[X_{10}\right]-0.1539
\end{aligned}
$$

Donde, $X_{7}$ es la suma del contenido $(\mathrm{g} / 100 \mathrm{~g}$ de proteína) de los aminoácidos treonina (Tre), valina (Val), metionina (Met), isoleucina (lle), leucina (Leu), fenilalanina (Fen) y lisina (Lis), y $X_{10}$ es la suma de $X_{7}$ y los contenidos ( $g / 100$ $g$ de proteína) de histidina (His), arginina (Arg) y triptófano (Trp). Ambas ecuaciones son aceptadas para la estimación de c-PER; sin embargo, como se puede observar la ecuación de PER $_{10}$ podría ser las más apropiada porque involucra una mayor cantidad de aminoácidos para su cálculo.

Valor biológico estimado. EI VB estimado fue calculado de acuerdo con Morup y Olesen (1976) utilizando la siguiente ecuación:

$V B=10^{2.15} \times L y s^{0.41} \times(P h e+T y r)^{0.60} \times(M e t+C y s)^{0.77} \times T h r^{2.4} \times T^{0} p^{0.21}$ Ec. 2

Donde cada símbolo de aminoácido representa la relación entre el porcentaje del aminoácido respecto al patrón de referencia de la FAO. 


\section{Diseño y análisis estadístico}

La evaluación estadística de los datos se realizó con un análisis de varianza de una vía, empleando una comparación de medias por el método de Duncan para los resultados obtenidos para las dos variedades de maíz mejoradas y las dos variedades predecesoras utilizando el paquete estadístico Statgraphics Centurion XVI.II (Montgomery, 2008).

\section{RESULTADOS Y DISCUSIÓN}

\section{Composición proximal de las variedades de maíz}

La composición proximal de las variedades predecesoras y los QPM se indica en la Tabla 1. La humedad en las variedades mejoradas resultó ser menor $(p<0.05)$ que el de las nativas, lo cual favorecería el almacenamiento de los granos pues podría disminuir el riesgo de aparición de hongos y otro tipo contaminación microbiana. Es posible afirmar esto puesto que, la norma del maíz para procesos de nixtamalización NMX-FF-034/1-SCFI-2002 establece un límite del $14 \%$ para minimizar dichos efectos. En contraste a otras variedades de maíz, los valores obtenidos fueron menores a los reportados por Gutiérrez et al. (2009) para híbridos QPM blanco y amarillo cuyos valores oscilaron entre el $13.6 \%$ y $14.3 \%$ para las variedades $\mathrm{H}-431$, A-Pantera y P-30G54; esto indica que para las variedades en estudio al presentar menos humedad se podría reducir uno de los efectos que sufren los maíces QPM, que comúnmente son susceptibles a plagas y a hongos, en donde el contenido de humedad es un factor determinante.

Comparando los valores de cenizas de cada grano híbrido con su control, no se encontraron diferencias estadísticas $(p>0.05)$. Los valores obtenidos en este estudio fueron ligeramente menores a los obtenidos por Gutiérrez et al. (2009) para híbridos QPM cuyos valores estuvieron comprendidos entre 1.6 y $1.7 \%$ para variedades de maíz amarillo y blanco, respectivamente. La cantidad de cenizas

Tabla 1. Composición química proximal de las variedades de maíz híbrido y predecesor (\% B.S.).

Table 1. Proximal chemical composition of the hybrid and predecessor corn varieties (\% B.S.).

\begin{tabular}{lcccc}
\hline Variedad & $\begin{array}{c}\text { Predecesor } \\
\text { Chichén Itzá }\end{array}$ & $\begin{array}{c}\text { Predecesor } \\
\text { Sac Béh }\end{array}$ & $\begin{array}{c}\text { Híbrido } \\
\text { Chichén Itzá }\end{array}$ & $\begin{array}{c}\text { Híbrido } \\
\text { Sac Béh }\end{array}$ \\
\hline Humedad & $8.48 \pm 0.19^{\mathrm{a}}$ & $7.69 \pm 0.02^{\mathrm{b}}$ & $6.68 \pm 0.07^{\mathrm{c}}$ & $6.77 \pm 0.070^{\mathrm{c}}$ \\
\hline Cenizas & $1.36 \pm 0.04^{\mathrm{b}}$ & $1.50 \pm 0.06^{\mathrm{a}}$ & $1.29 \pm 0.06^{\mathrm{b}}$ & $1.49 \pm 0.01^{\mathrm{ab}}$ \\
\hline Grasa cruda & $5.01 \pm 0.04^{\mathrm{b}}$ & $5.05 \pm 0.08^{\mathrm{b}}$ & $6.93 \pm 0.05^{\mathrm{a}}$ & $7.07 \pm 0.15^{\mathrm{a}}$ \\
\hline $\begin{array}{l}\text { Proteína } \\
\text { cruda }\end{array}$ & $10.78 \pm 0.20^{\mathrm{b}}$ & $9.77 \pm 0.03^{\mathrm{c}}$ & $11.12 \pm 0.01^{\mathrm{a}}$ & $11.37 \pm 0.02^{\mathrm{a}}$ \\
\hline Fibra cruda & $3.09 \pm 0.04^{\mathrm{a}}$ & $2.87 \pm 0.04^{\mathrm{a}}$ & $2.42 \pm 0.22^{\mathrm{a}}$ & $2.71 \pm 0.029^{\mathrm{a}}$ \\
\hline ELN* & $79.76 \pm 0.09^{\mathrm{b}}$ & $80.81 \pm 0.20^{\mathrm{a}}$ & $78.24 \pm 0.12^{\mathrm{c}}$ & $77.36 \pm 0.43^{\mathrm{d}}$ \\
\hline
\end{tabular}

a-d Letras diferentes en la misma fila indican diferencia significativa $(p<0.05)$. Los valores son promedios \pm desviación estándar. * ELN (Extracto Libre de Nitrógeno). de la variedad amarilla Chichén Itzá (1.3 \%) en comparación con otras variedades amarillas locales del estado de Yucatán en México fue menor al de Xmejen nal (1.7\%), T'síit bakal (1.5\%) e Xnuuk nal (1.6\%). La variedad Sac Béh con $1.5 \%$ de ceniza comparado con variedades de maíz blanco fue mayor que la variedad $\mathrm{Nal}$ t'eel (1.4\%), similar a Xmejen nal (1.5\%) e Xnuuk nal (1.5 \%) y menor que T'síit bakal (1.8 \%) (Cázares et al., 2015).

Respecto al contenido de fibra cruda, no se encontraron diferencias estadísticas significativas ( $p>0.05$ ), indicando que no existieron cambios en cuanto a la proporción de este componente entre las variedades estudiadas, que en promedio fue $2.7 \%$. Los valores hallados fueron mayores a los reportados por Cázares et al. (2015) para variedades blancas y amarillas nativas de Yucatán (Nal t'eel, Xmejen nal, T'siit bakal e Xnuuk nal) con contenidos menores al $2 \%$, indicando que el consumo de éstos maíces, aportarán más fibra que otras variedades de la misma región con los beneficios fisiológicos y metabólicos que tiene el consumo de éste componente alimentario.

Para el contenido de grasa se encontró que los maíces híbridos fueron estadísticamente iguales entre ellos ( $p>0.05$ ), pero superiores a sus variedades predecesoras, teniendo estos últimos valores de $5 \%$ semejantes a los reportados para maíz normal cuyo contenido ha sido reportado entre el 3-5\% (Gutiérrez et al., 2009; Sanjeev et al., 2014; Mohammad et al., 2018). Las variedades híbridas en cambio incrementaron el contenido de grasa a un $7 \%$ que resultaron ser mayores a los encontrados por Gutiérrez et al. (2009) que obtuvo $5 \%$ para dos híbridos blancos y $4.39 \%$ para un híbrido amarillo. Esto posiblemente fue resultado del efecto del desarrollo del gen opaco-2, lo cual podría ser beneficioso para la salud debido a la composición de ácidos grasos presentes en los lípidos del maíz.

Los resultados de proteína mostraron diferencia significativa $(p<0.05)$ entre los granos híbridos y sus respectivos predecesores nativos. En el caso del Chichén Itzá presentó un incremento de $0.34 \%$ entre el nativo y el híbrido y en el caso de Sac Béh incrementó $1.6 \%$. Con respecto a otras variedades nativas, los porcentajes obtenidos se encuentran entre valores aceptables, pues en el estudio realizado por Cázares et al. (2015) se reportaron porcentajes de proteína que comprendían entre el 9.3 y $12.5 \%$ para las variedades blancas y amarillas de Nal t'eel, Xmejen nal, T'sít bakal e Xnuuk nal. Los híbridos del presente estudio demostraron un mayor contenido de proteína en comparación al estudio realizado por Gutiérrez et al. (2009) en donde los híbridos QPM comprendían valores entre 8.2 y $9.4 \%$.

El maíz predecesor del Chichén Itzá (amarillo) presentó $79.76 \%$ de carbohidratos, porcentaje similar a la variedad Xmejen nal (80.66 \%) y menor a T'sít bakal (82.12\%) e Xnuuk nal $(82.76 \%)$ que son nativas de Yucatán, México. Por otra parte, el híbrido Chichén Itzá presentó valores menores a las variedades anteriormente mencionadas con $78.23 \%$. La variedad predecesora del maíz Sac Béh (blanco) presentó $80.81 \%$ de carbohidratos, similar a Xmejen nal $(81.11 \%)$ y 
menor a Nal t'eel (82.23 \%), T'síit bakal (83.21 \%) e Xnuuk nal (82.63\%), en cambio el híbrido Sac Beh presentó un 77.35 $\%$, el cual fue menor a las variedades blancas mencionadas con anterioridad (Cázares et al., 2015). Los valores inferiores obtenidos para los híbridos pueden explicarse debido a que el aumento de lípidos y proteína tiene un efecto contrario en la cantidad de almidón de los granos de maíz, estimados en el ELN.

Al comparar la composición proximal en la conversión de variedades de maíz nativo a maíz QPM, se encontró principalmente tendencias a un aumento del contenido de grasa y disminución de carbohidratos (Tabla 1), se ha reportado por Val et al. (2009) que aquellas variedades que poseen mayor contenido de aceite generalmente poseen mayores cantidades de proteína y lisina. Se podría asociar que con la modificación con el gen opaco-2, se logra un incremento en el contenido de aceite, y específicamente en los maíces Sac Béh y Chichén Itzá también presentaron un aumento en proteína comparado con su origen nativo, por lo que la redistribución en la composición químico proximal fue un indicativo que se logró la conversión de las variedades nativas.

\section{Minerales $\mathrm{Ca}$, Fe, $\mathrm{K}, \mathrm{Mg}, \mathrm{Na}, \mathrm{P}$}

En la tabla 2 se presenta el contenido de minerales hallado en las variedades de maíz Sac Béh y Chichén Itzá, donde a excepción de Fe y Mg, no se observaron diferencias estadísticamente significativas ( $p>0.05$ ) entre las variedades híbridas y nativas.

Los principales minerales del maíz fueron $\mathrm{P}, \mathrm{K}$ y Mg al ser los más abundantes en el grano, puesto que generalmente se encuentran como sales de ácido fítico, y los elementos menos abundantes fueron $\mathrm{Na}$, Ca y Fe al estar en cantidades mínimas; sin embargo, el contenido de Ca suele incrementarse después del proceso de nixtamalización donde se emplea CaO (Gwirtz y García, 2014). El contenido mineral de las va-

Tabla 2. Contenido de minerales $(\mathrm{mg} / 100 \mathrm{~g})$ de las variedades de maíz híbrido y predecesor.

Table 2. Minerals content (mg / $100 \mathrm{~g}$ ) of the hybrid and predecessor maize varieties.

\begin{tabular}{lcccc}
\hline Muestra & $\begin{array}{c}\text { Predecesor } \\
\text { Chichén } \\
\text { Itzá }\end{array}$ & $\begin{array}{c}\text { Predecesor } \\
\text { Sac Béh }\end{array}$ & $\begin{array}{c}\text { Híbrido Chi- } \\
\text { chén Itzá }\end{array}$ & $\begin{array}{c}\text { Híbrido Sac } \\
\text { Béh }\end{array}$ \\
\hline $\mathrm{Ca}$ & $8.80 \pm 0.51^{\mathrm{a}}$ & $9.96 \pm 2.49^{\mathrm{a}}$ & $10.29 \pm 2.52^{\mathrm{a}}$ & $9.45 \pm 0.55^{\mathrm{a}}$ \\
$\mathrm{Fe}$ & $3.65 \pm 0.03^{\mathrm{b}}$ & $5.15 \pm 0.51^{\mathrm{a}}$ & $4.03 \pm 0.30^{\mathrm{b}}$ & $4.28 \pm 0.67^{\mathrm{b}}$ \\
\hline $\mathrm{K}$ & $255.74 \pm 8.12^{\mathrm{a}}$ & $299.35 \pm 29.17^{\mathrm{a}}$ & $261.61 \pm 8.85^{\mathrm{a}}$ & $268.78 \pm 27.47^{\mathrm{a}}$ \\
\hline $\mathrm{Mg}$ & $100.99 \pm 4.07^{\mathrm{a}}$ & $106.20 \pm 1.61^{\mathrm{a}}$ & $108.11 \pm 3.68^{\mathrm{a}}$ & $103.94 \pm 3.32^{\mathrm{a}}$ \\
\hline $\mathrm{Na}$ & $35.06 \pm 1.60^{\mathrm{b}}$ & $54.55 \pm 3.13^{\mathrm{a}}$ & $41.51 \pm 6.40^{\mathrm{b}}$ & $37.22 \pm 4.02^{\mathrm{b}}$ \\
\hline $\mathrm{P}$ & $337.56 \pm 8.04^{\mathrm{a}}$ & $352.72 \pm 0.34^{\mathrm{a}}$ & $337.09 \pm 15.96^{\mathrm{a}}$ & $334.90 \pm 12.39^{\mathrm{a}}$ \\
\hline
\end{tabular}

a-b Letras diferentes en la misma fila indican diferencia significativa $(p<0.05)$. Los valores son promedios \pm desviación estándar, Ca: Calcio, Fe: Hierro, K: Potasio; Mg: Magnesio, Na: Sodio, P: Fósforo riedades en estudio presentó similitudes con la composición de los minerales mayoritarios $\mathrm{P}, \mathrm{K}$ y Mg hallado por Bódi et al. (2008) para maíz rojo y azul, no siendo de la misma manera para los demás elementos como $\mathrm{Ca}$, Fe y $\mathrm{Na}$. Para maíz rojo, estos autores reportan $310.56 \mathrm{mg} / 100 \mathrm{~g}$ para $\mathrm{P}, 264.78 .8$ $\mathrm{mg} / 100 \mathrm{~g}$ para K y $101.81 \mathrm{mg} / 100 \mathrm{~g}$ para Mg. En tanto, el contenido de Ca para las variedades amarillas y blancas de este estudio fueron menores respecto a lo reportado (12.69 $\mathrm{mg} / 100 \mathrm{~g}$ ). También se observa un mayor contenido de $\mathrm{Na}$ en las variedades de dicho estudio con $12.8 \mathrm{mg} / 100 \mathrm{~g}$ y por último, en el caso de $\mathrm{Fe}(3.58 \mathrm{mg} / 100 \mathrm{~g})$ sólo las variedades híbridas y el nativo Chichén Itzá fueron similares, pues el nativo Sac Béh resultó con mayor contenido. En comparación con las variedades de maíz azul (Bódi et al., 2008), se observó la misma tendencia con respecto a lo reportado para $\mathrm{P}$ y K (352.77 y $314.82 \mathrm{mg} / 100 \mathrm{~g}$, respectivamente). Para Mg se observó una cantidad ligeramente menor en los maíces en estudio respecto a lo reportado $(121.96 \mathrm{mg} / 100 \mathrm{~g})$, en tanto el contenido de Ca resultó menor a lo hallado con 11.63 $\mathrm{mg} / 100 \mathrm{~g}$. Los niveles de Na resultaron mayores a los de dicho estudio (13.97 mg/100 g) y en caso del Fe se observa el mismo comportamiento comparado a lo reportado.

Sólo la variedad nativa Sac Béh presentó mayor contenido de $\mathrm{Fe}$ y $\mathrm{Na}$ en comparación del resto que resultaron ser estadísticamente iguales entre sí ( $p>0.05$ ). Dicho comportamiento podría ser explicado con base en lo señalado por Menkir (2008) y Martínez et al. (2017) respecto a que el contenido mineral depende de la genética, ya que los nutrientes difieren de una variedad a otra, y probablemente de las condiciones ambientales en las que se encuentran cultivadas como los nutrientes del suelo. Se puede suponer que al estar en las mismas condiciones se obtuvo un contenido mineral similar.

\section{Perfil de ácidos grasos}

Los híbridos Chichén Itzá y Sac Béh, al presentar un contenido de aceite superior al $6 \%$ pueden ser considerados como maíz de alto aceite (HOC por sus siglas en inglés de High-Oil Corn). Algunas características importantes observadas en las variedades HOC son su mayor contenido de proteína y mayor cantidad de algunos aminoácidos esenciales como Lys, Thr y Met (Singh et al., 2013; Preciado et al., 2018). El aumento de grasa indica que puede haber cambios en la composición de ácidos grasos, como lo observado en la tabla 3 , en donde hay un aumento en el total de ácidos grasos insaturados y por consiguiente una disminución en los ácidos grasos saturados. De manera específica se observó menor contenido de ácido palmítico para Sac Béh y Chichén Itzá. En el caso de Sac Béh también se da el mismo efecto para el ácido esteárico; por el contrario, se aprecia mayor contenido de ácido oleico indicando que el efecto del gen opaco-2 o más bien con el mejoramiento genético de las variedades, se podrían dar cambios en la síntesis de ácidos grasos en el grano que involucran mayormente al ácido palmítico y oleico. Por otra parte, los ácidos grasos insaturados de mayor interés fueron el ácido linoleico y linolénico y de manera general 
Tabla 3. Perfil de ácidos grasos de las variedades de maíz híbrido y predecesor. Table 3. Fatty acid profile of the hybrid and predecessor maize varieties.

\begin{tabular}{|c|c|c|c|c|c|}
\hline Ácido graso (\%) & Abreviatura & Predecesor Chichén Itzá & Predecesor Sac Béh & Híbrido Chichén Itzá & Híbrido Sac Béh \\
\hline Ac. Palmítico & C16:0 & $20.14 \pm 0.58^{\mathrm{a}}$ & $19.52 \pm 0.73^{\mathrm{ab}}$ & $18.34 \pm 0.26^{b}$ & $18.49 \pm 0.10^{b}$ \\
\hline Ac. Palmitoleico & C16:1 & $0.08 \pm 0.00^{b}$ & $0.08 \pm 0.01^{b}$ & $0.06 \pm 0.01^{c}$ & $0.10 \pm 0.01^{\mathrm{a}}$ \\
\hline Ac. Margárico & $\mathrm{C} 17: 0$ & $0.09 \pm 0.01^{\mathrm{a}}$ & $0.08 \pm 0.01^{\mathrm{ab}}$ & $0.07 \pm 0.01^{\mathrm{bc}}$ & $0.05 \pm 0.01^{c}$ \\
\hline Ac. Esteárico & C18:0 & $5.26 \pm 0.17^{\mathrm{a}}$ & $5.00 \pm 0.19^{\mathrm{a}}$ & $5.03 \pm 0.21^{\mathrm{a}}$ & $4.21 \pm 0.11^{b}$ \\
\hline Ac. Oleico & C18:1 & $33.77 \pm 0.34^{b}$ & $31.70 \pm 0.70^{c}$ & $35.88 \pm 0.29^{\mathrm{a}}$ & $33.65 \pm 0.16^{b}$ \\
\hline Ac. Linoleico & C18:2 & $38.53 \pm 0.08^{b}$ & $41.52 \pm 0.33^{\mathrm{a}}$ & $38.64 \pm 0.26^{b}$ & $41.87 \pm 0.37^{\mathrm{a}}$ \\
\hline Ac. Araquidíco & C20:0 & $0.62 \pm 0.02^{\mathrm{a}}$ & $0.64 \pm 0.01^{\mathrm{a}}$ & $0.65 \pm 0.01^{\mathrm{a}}$ & $0.54 \pm 0.04^{b}$ \\
\hline Ac. Eicosenoico & C20:1 & $0.18 \pm 0.01^{\mathrm{a}}$ & $0.15 \pm 0.03^{a}$ & $0.16 \pm 0.04^{a}$ & $0.12 \pm 0.01^{\mathrm{a}}$ \\
\hline Ac. Linolénico & $\mathrm{C} 18: 3$ & $0.84 \pm 0.04^{\mathrm{a}}$ & $0.82 \pm 0.03^{\mathrm{a}}$ & $0.78 \pm 0.05^{\mathrm{a}}$ & $0.66 \pm 0.01^{b}$ \\
\hline Ac. Behénico & $\mathrm{C} 22: 0$ & $0.20 \pm 0.05^{\mathrm{a}}$ & $0.20 \pm 0.02^{\mathrm{a}}$ & $0.17 \pm 0.01^{\mathrm{a}}$ & $0.15 \pm 0.01^{\mathrm{a}}$ \\
\hline Ac. Lignocérico & C24:0 & $0.29 \pm 0.03^{\mathrm{a}}$ & $0.29 \pm 0.04^{\mathrm{a}}$ & $0.23 \pm 0.01^{\mathrm{ab}}$ & $0.18 \pm 0.01^{b}$ \\
\hline SFA & & $26.60 \pm 0.30^{\mathrm{a}}$ & $25.74 \pm 0.97^{\mathrm{ab}}$ & $24.48 \pm 0.46^{\mathrm{bc}}$ & $23.61 \pm 0.23^{c}$ \\
\hline MUFA + PUFA & & $73.40 \pm 0.30^{\mathrm{ac}}$ & $74.26 \pm 0.97^{\mathrm{bc}}$ & $75.52 \pm 0.46^{\mathrm{ab}}$ & $76.39 \pm 0.23^{\mathrm{a}}$ \\
\hline MUFA & & $34.03 \pm 0.34^{\mathrm{ab}}$ & $31.93 \pm 0.67^{c}$ & $36.10 \pm 0.24^{\mathrm{a}}$ & $33.86 \pm 0.15^{b}$ \\
\hline PUFA & & $39.37 \pm 0.03^{\mathrm{ab}}$ & $42.34 \pm 0.30^{\mathrm{a}}$ & $39.42 \pm 0.21^{b}$ & $42.53 \pm 0.38^{\mathrm{a}}$ \\
\hline
\end{tabular}

a-c Letras diferentes en la misma fila indican diferencia significativa $(p<0.05)$. Los valores son promedios \pm desviación estándar $S F A=$ Ácidos

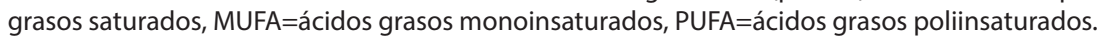

permanecieron sin cambios, a excepción en el linolénico específicamente en la variedad Sac Béh que disminuyó un 20 $\%$.

Ignjatovic et al. (2015) determinaron el perfil de ácidos grasos de variedades de maíz con alto contenido de aceite encontrando valores en común con los híbridos del presente estudio, salvo la diferencia en contenido de ácido palmítico y esteárico. En dicho estudio, se encontró entre 1.5-3.3\% de ácido palmítico y de 9-13\% de ácido esteárico valores inferiores a los encontrados en las variedades Chichen Itzá y Sac Béh; el contenido de los ácidos oleico, linoleico y linolénico oscilaron entre los valores de $23.9-45.2 \%, 40-62 \%$ y $0.52-0.82$ $\%$ respectivamente semejantes a los resultados encontrados a los materiales del presente estudio. Los autores también reportaron ácidos grasos trazas como el palmitoleico, margárico, araquidíco, eicosenoico, behénico, lignocérico y eicosatrienoico. En un estudio realizado por Sanjeev et al. (2014) se encontró el perfil de ácidos grasos de variedades de maíz, en donde se destaca un grupo de híbridos QPM que contenían $15.14 \%$ de ácido palmítico, $3.85 \%$ de ácido esteárico, 33.54 $\%$ de ácido oleico y $44.19 \%$ de ácido linoleico, lo cual indica que los híbridos y nativos de este estudio presentan mayor contenido de los ácidos palmítico y esteárico, un contenido similar de ácido oleico y menor cantidad de ácido linoleico lo cual puede ser debido a la variedad.

El contenido de ácidos grasos insaturados resultó ser estadísticamente diferente $(p<0.05)$ y se observó un aumento en las variedades híbridas, principalmente en MUFA donde se encontró diferencia significativa $(p<0.05)$ entre variedades y resultando mayores en los híbridos; por otra parte, las variedades Sac Béh y Chichén Itzá mantuvieron sus niveles de PUFA cuando se dio la conversión a QPM. Lo anterior es de beneficio para la salud ya que la FAO recomienda que es mejor consumir PUFA y MUFA en lugar de SFA para mejorar los niveles de colesterol HDL y prevenir enfermedades coronarias, además de que el ácido linoleico y linolénico (PUFA) son esenciales para para el ser humano, es decir que no pueden ser sintetizados por el organismo humano y tienen efectos positivos para el crecimiento y desarrollo de los infantes; por otra parte, aunque el ácido esteárico (SFA) que tiene una abundancia de $5 \%$, no afecta a la salud de manera negativa, pues existe evidencia de que no incrementa los niveles de colesterol asociado a las LDL. 


\section{Perfil de aminoácidos}

El perfil de aminoácidos de los híbridos Chichén Itzá y Sac Béh, con sus respectivos controles (Tabla 4), puso en evidencia cambios estadísticamente significativos $(p<0.05)$ por efecto del gen opaco-2. Se observó un aumento en el contenido de ciertos aminoácidos, como el caso de la His en la variedad híbrida Chichén Itzá que incrementó de forma significativa $(p<0.05)$ con respecto a su predecesor, de igual forma la lle aumentó de forma significativa $(p<0.05)$ aproximadamente 10 veces su valor en ambas variedades híbridas. Efecto similar ocurrió con la Fen ya que aumentó 13 veces en la variedad Chichén Itzá y 7 veces en la variedad Sac Béh lo cual mejora con respecto a la relación con la Tir, el cual es un aminoácido no esencial y que puede ser sintetizado a partir de Fen según Shewry (2007).

En cuanto a los aminoácidos Lis y Trp, se observaron cambios positivos al aumentar la Lis casi el doble y el Trp 10 veces más en comparación de lo que se halló en las variedades predecesoras. Lo anterior indica que las variedades híbridas cuentan con un mejor contenido de la mayoría de los aminoácidos esenciales respecto a las variedades predecesoras, por tanto, tienen una proteína de mejor calidad.
Este resultado es importante a pesar de que disminuyó el contenido de Val en un 29 \% en la variedad Chichén Itzá y en un $88 \%$ en la variedad Sac Béh.

Lisina aumentó 1.8 en el maíz QPM, cubriendo casi el 50\% del patrón de referencia de la FAO. En el caso de Trp, la concentración aumentó 8 veces en el híbrido Chichén Itzá y 12 veces en Sac Béh con respecto a sus predecesores, cubriendo así el 29.4 \% y el 41.2 \% del patrón de referencia respectivamente. El aumento de Lis y Trp pudiera atribuirse al desarrollo del gen opaco-2, el cual, inhibe de la síntesis de zeínas, que contienen en cantidades mínimas de ambos aminoácidos, principalmente Trp. De igual manera el gen opaco-2 promueve la síntesis de otras fracciones proteicas (albúminas, globulinas y glutelinas), de tal forma que duplican el contenido de Lis y aumentan la cantidad de Trp en el grano (Shewry, 2007; Li y Vassal, 2010).

En contraste con otras variedades nativas del estado de Yucatán, se observa que la cantidad de Lis en los híbridos (2.54 g de AA/100 g de proteína Chichén Itzá y $2.72 \mathrm{~g}$ de AA/100 g de proteína Sac Béh) fue menor a la reportada por Cazáres et al. (2015) para las variedades nativas del estado de Yucatán Nal t'eel (2.78 g de AA/100 g de proteína), Xmejen

Tabla 4. Perfil de aminoácidos ( $\mathrm{g}$ de $\mathrm{AA} / 100 \mathrm{~g}$ de proteína) de las variedades de maíz híbrido y predecesor.

Table 4. Amino acid profile ( $\mathrm{g}$ of AA / $100 \mathrm{~g}$ of protein) of the hybrid and predecessor maize varieties.

\begin{tabular}{|c|c|c|c|c|c|}
\hline Aminoácido & $\begin{array}{l}\text { Predecesor } \\
\text { Chichén Itzá }\end{array}$ & $\begin{array}{l}\text { Predecesor } \\
\text { Sac Béh }\end{array}$ & Híbrido Chichén Itzá & Híbrido Sac Béh & Patrón FAO* \\
\hline Histidina & $1.72 \pm 0.09^{c}$ & $7.45 \pm 0.24^{\mathrm{a}}$ & $2.60 \pm 0.12^{b}$ & $2.48 \pm 0.14^{b}$ & 2 \\
\hline Treonina & $7.80 \pm 0.01^{\mathrm{a}}$ & $4.49 \pm 0.23^{c}$ & $4.45 \pm 0.41^{c}$ & $5.26 \pm 0.24^{b}$ & 3.1 \\
\hline Valina & $2.22 \pm 0.16^{b}$ & $10.48 \pm 0.07^{a}$ & $1.57 \pm 0.22^{c}$ & $1.33 \pm 0.05^{c}$ & 4.3 \\
\hline Metionina & $13.01 \pm 0.09^{a}$ & $7.21 \pm 0.25^{c}$ & $10.26 \pm 0.36^{b}$ & $6.37 \pm 0.13^{d}$ & - \\
\hline Isoleucina & $0.36 \pm 0.01^{b}$ & $0.25 \pm 0.05^{b}$ & $2.98 \pm 0.41^{a}$ & $2.67 \pm 0.23^{a}$ & 3.2 \\
\hline Leucina & $11.79 \pm 0.05^{\mathrm{a}}$ & $8.78 \pm 0.27^{d}$ & $11.01 \pm 0.01^{b}$ & $10.07 \pm 0.20^{c}$ & 6.6 \\
\hline Fenilalanina & $0.33 \pm 0.01^{b}$ & $0.57 \pm 0.18^{b}$ & $4.42 \pm 0.99^{a}$ & $3.87 \pm 0.25^{a}$ & - \\
\hline Lisina & $1.38 \pm 0.11^{b}$ & $1.49 \pm 0.02^{b}$ & $2.54 \pm 0.16^{a}$ & $2.72 \pm 0.14^{a}$ & 5.7 \\
\hline Triptófano & $0.03 \pm 0.006^{c}$ & $0.03 \pm 0.002^{c}$ & $0.25 \pm 0.004^{b}$ & $0.35 \pm 0.006^{a}$ & 0.85 \\
\hline Cistina & $3.54 \pm 0.73^{a}$ & $3.05 \pm 0.14^{\mathrm{ab}}$ & $3.34 \pm 0.07^{a}$ & $2.44 \pm 0.03^{b}$ & - \\
\hline Tirosina & $5.91 \pm 0.45^{a}$ & $4.37 \pm 0.22^{b}$ & $1.95 \pm 0.14^{c}$ & $1.67 \pm 0.04^{c}$ & - \\
\hline SAA & $16.55 \pm 0.81^{\mathrm{a}}$ & $10.26 \pm 0.38^{c}$ & $13.6 \pm 0.42^{b}$ & $8.81 \pm 0.16^{d}$ & 2.7 \\
\hline AAA & $6.24 \pm 0.17^{a}$ & $4.94 \pm 0.09^{b}$ & $6.37 \pm 0.23^{a}$ & $5.54 \pm 0.31^{\mathrm{ab}}$ & 5.2 \\
\hline$A A E$ & $48.08 \pm 1.72^{a}$ & $48.17 \pm 1.50^{a}$ & $45.36 \pm 1.89^{c}$ & $39.24 \pm 1.50^{d}$ & \\
\hline Arginina & $5.59 \pm 0.28^{c}$ & $1.44 \pm 0.06^{d}$ & $14.47 \pm 0.85^{a}$ & $8.39 \pm 0.10^{b}$ & \\
\hline Serina & $6.05 \pm 0.13^{c}$ & $7.71 \pm 0.13^{b}$ & $4.02 \pm 0.12^{d}$ & $10.70 \pm 0.22^{a}$ & \\
\hline Ac. Aspártico & $19.08 \pm 0.48^{a}$ & $9.07 \pm 0.43^{c}$ & $11.79 \pm 0.93^{b}$ & $8.92 \pm 0.37^{c}$ & \\
\hline Ac. Glutámico & $10.89 \pm 0.38^{a}$ & $10.50 \pm 0.33^{a}$ & $8.10 \pm 0.17^{b}$ & $3.20 \pm 0.13^{c}$ & \\
\hline Glicina & $1.41 \pm 0.11^{d}$ & $1.86 \pm 0.11^{c}$ & $2.42 \pm 0.18^{b}$ & $3.08 \pm 0.15^{\mathrm{a}}$ & \\
\hline Alanina & $0.40 \pm 0.08^{c}$ & $8.22 \pm 0.65^{b}$ & $0.49 \pm 0.27^{c}$ & $11.76 \pm 0.15^{\mathrm{a}}$ & \\
\hline Prolina & $8.50 \pm 0.22^{b}$ & $13.03 \pm 1.55^{\mathrm{a}}$ & $13.35 \pm 1.03^{a}$ & $14.72 \pm 0.13^{a}$ & \\
\hline AANE & 51.91 & 51.83 & 54.64 & 60.76 & \\
\hline Total & 100 & 100 & 100 & 100 & \\
\hline
\end{tabular}

$\mathrm{SAA}=$ Aminoácidos azufrados (Met+Cis), $\mathrm{AAA}=$ Aminoácidos aromáticos (Fen+Tir), $\mathrm{AAE}=$ Total de aminoácidos esenciales según el patrón $\mathrm{FAO} / \mathrm{ONU} / \mathrm{WHO}, \mathrm{AANE}=$ Total de aminoácidos no esenciales. Los valores son promedios \pm desviación estándar ${ }^{\text {a-d }}$ Letras diferentes dentro de la misma fila indican diferencia significativa $(p<0.05)$. *Patrón FAO/WHO/ONU 2007 para niños de 6 meses a 3 años. 
nal (2.92 g de AA/100 g de proteína), T'síit bakal (2.97 g de AA/100 g de proteína) e Xnuuk nal (2.97 g de AA/100 g de proteína), pero mayor a las predecesoras nativas Chichén Itzá (1.38 g de AA/100 g de proteína) y Sac Béh ( 1.49 g de AA/100 $\mathrm{g}$ de proteína). Por otra parte, el contenido de Trp fue menor al hallado en el estudio de Cazáres et al. (2015) cuyos valores fueron de 0.85 a $0.95 \mathrm{~g}$ de AA/100 g de proteína, pero mayor al de los predecesores. En un estudio realizado por Mendoza et al. (2006) para variedades QPM, se presentan cantidades de Lis similares a variedades QPM blanco denominadas $\mathrm{QPMV}_{5}$ y $\mathrm{QPMV}_{6}$ con 2.46 y $2.30 \mathrm{~g}$ de AA/100 g de proteína, y valores mayores al de maíz normal $V_{1}$ blanco con $2.05 \mathrm{~g}$ de AA/100 $\mathrm{g}$ de proteína y $V_{2}$ amarillo $1.64 \mathrm{~g}$ de AA/100 g de proteína, mostrando mejora sobre maíz normal, al igual que en este estudio. En el caso de Trp, los híbridos de este estudio presentan menores cantidades que incluso las variedades normales $V_{1} 0.41$ y $V_{2} 0.44 \mathrm{~g}$ de AA/100 g de proteína; sin embargo, aunque se observó una mejora en las variedades Sac Béh y Chichén Itzá, es necesario realizar más esfuerzos en la búsqueda de amentar la calidad de la proteína del grano.

La modificación de las proteínas del endospermo (y con ello el perfil de aminoácidos) se puede ver gracias al desarrollo del gen opaco-2, resultando en la reducción de proteínas tipo zeína y por tanto produciendo mayores cantidades de Lis y Trp. De igual forma al haber una redistribución en el perfil de aminoácidos, se puede hipotetizar que se dio un aumento en el contenido de proteínas no-zeínas que contienen mayores concentraciones de estos aminoácidos esenciales y de otros como lle y Fen.

\section{Calidad de la proteína}

Digestibilidad "in vitro" de proteínas. Los resultados indicaron que hubo diferencia significativa $(p<0.05)$ entre las cuatro variedades evaluadas. De igual forma se encontró un incremento en la digestibilidad de aproximadamente $4 \%$ en cada variedad híbrida con respecto a su variedad predecesora nativa. La variedad Chichén Itzá presentó un incremento en la digestibilidad de 71.14 a $75.15 \%$ y Sac Béh de 72.07 a $76.48 \%$ al pasar de nativo a QPM. Esto indica que adicional a la mejora de la calidad de proteína por el contenido de aminoácidos, también se mejoró la digestibilidad que se tiene de éstos. Asimismo, dicho valor debe incrementar cuando se sometan a procesos tecnológicos de transformación como cocción, nixtamalización o extrusión de los granos.

El porcentaje de digestibilidad "in vitro" hallado en este estudio para la variedad híbrida Chichén Itzá fue similar al reportado por Gutiérrez et al. (2009) para harina cruda de maíz QPM con un valor de $75.48 \%$, y en caso de Sac Béh resultó ser mayor que en ese mismo estudio. En comparación a otro estudio realizado Cuevas et al. (2006) para harina de maíz QPM, ambas variedades presentan valores menores de digestibilidad, pues en ese estudio se obtuvo una digestibilidad "in vitro" de $78.06 \%$. El aumento en la digestibilidad pudo deberse a una disminución de las proteínas tipo zeína, que son hidrofóbicas y menos digeribles por sistemas enzimáticos como la pepsina y tripsina/quimotripsina, por lo cual, al aumentar las proteínas no-zeína que son más digeribles (principalmente las albúminas y globulinas del maíz) se observa una mayor digestibilidad en los híbridos que en las nativas ricas en zeína (Kriz, 2009).

Cómputo Químico. Se observó que las variedades híbridas cubrieron mejor los requerimientos del estándar FAO/WHO/ONU para niños de 6 meses a 3 años (Tabla 5). Esta afirmación es posible para las variedades híbridas Sac Béh y Chichén Itzá, pues se encontró que los aminoácidos His, Leu, aminoácidos azufrados, aminoácidos aromáticos y Tre se cubren en $100 \%$. En la variedad Chichén Itzá se logró un aumento del $86 \%$ al $100 \%$ en His al convertirse a QPM; este aumento en el cómputo químico fue muy evidente en lle, ya que el maíz nativo Chichén Itzá pasó de cubrir el $11.25 \%$ de las necesidades nutrimentales a $91.14 \%$ con el maíz híbrido de esa variedad; y de $7.81 \%$ a $85.53 \%$ del nativo al híbrido del Sac Béh. Por otra parte, se observa que el contenido de Val para Chichén Itzá y Sac Béh no se cubre al igual que ocurre con Lis y Trp.

Puntaje de aminoácidos corregido con digestibilidad de proteínas (PDCAAS). Los valores del PDCAAS es uno de los métodos recomendados por la FAO para evaluar la calidad de una proteína, ya que indican el aprovechamiento de los aminoácidos, principalmente los limitantes (Schaarfsma, 2005). El aminoácido limitante en las variedades predecesoras nativas Sac Béh y Chichén Itzá, así como en el híbrido Chichén Itzá fue el Trp. En caso del híbrido Sac Béh fue Val el aminoácido limitante, mismo que normalmente es cubierto para otras variedades de maíz. Gutiérrez et al. (2008) reportan un valor de PDCAAS de $54.2 \%$ para la variedad QPM V-537 y $27 \%$ para la harina de maíz comercial, siendo Lis el aminoácido limitante en ambos casos. Ambos valores reportados fueron superiores a los reportados en este estudio con 22.10 y $23.66 \%$ para Sac Béh y Chichén Itzá QPMs, por lo que se puede decir que, a pesar del aumento de Lis y Trp en los híbridos, no logran satisfacer los requerimientos del patrón, ni presentan valores de PDCAAS mayores a otros híbridos QPM como V-537. Sin embargo, es evidente la mejora del PDCAAS ya que dichos valores fueron 9 veces mayores en las variedades híbridas con respecto a las nativas (2.51-2.54\%). Aunque el puntaje para el caso de Trp en los híbridos cubre cerca del $29 \%$ y $41 \%$ para Chichén Itzá y Sac Béh respectivamente, el aprovechamiento de este aminoácido se ve afectado por la digestibilidad, factor que influye en la utilización de la proteína y por ende de todos los aminoácidos que la conforman. De igual forma lo hallado indica que se requieren más esfuerzos en busca de mejorar los niveles de Lis, Trp y Val en estas variedades, pues el maíz es un alimento básico en las comunidades rurales y se debe tomar en cuenta el PDCAAS como parámetro para determinar si se está cubriendo el objetivo de satisfacer las necesidades nutrimentales en cuanto al requerimiento de proteínas.

Relación de eficiencia de proteína calculada (c-PER). En la Figura 1 se observan los resultados obtenidos de $\mathrm{PER}_{7}$ y $\mathrm{PER}_{10}$ que surgieron a partir de las ecuaciones de Lee et al. (1978). 


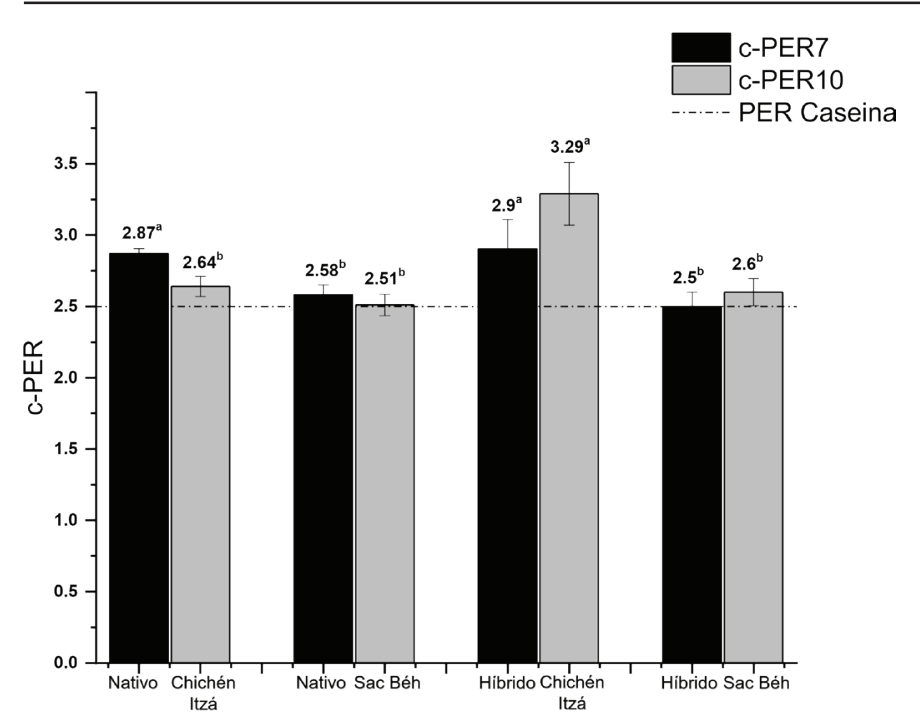

Figura 1. Valores de $\mathrm{PER}_{7}$ y $\mathrm{PER}{ }_{10}$ para las variedades de maíz híbrido y predecesor. ${ }^{\mathrm{a}-\mathrm{b}}$ Letras diferentes indican diferencia significativa.

Figure 1. $\mathrm{PER}_{7}$ and $\mathrm{PER}_{10}$ values for hybrid and predecessor maize varieties. a-b Different letters indicate significant difference.

Los valores obtenidos para $\mathrm{PER}_{7}$ resultaron ser estadísticamente iguales ( $p>0.05$ ) debido probablemente a que esta ecuación toma en cuenta la sumatoria del contenido de siete aminoácidos esenciales sin considerar la proporción entre ellos. En el caso de $\mathrm{PER}_{10^{\prime}}$ la variedad híbrida Chichén Itzá obtuvo un mayor valor sobre la nativa, lo cual puede atribuirse al aumento en la concentración de Arg, His y Trp observados en el perfil de aminoácidos (Tabla 4). Por otra parte, los valores de PER $_{10}$ en Sac Béh resultaron ser estadísti- camente iguales ( $p>0.05$ ) entre la variedad híbrida y la nativa. Los valores c-PER hallados en este estudio indican que son proteínas de buena calidad al ser superiores al valor de la caseína cuya PER es de 2.5 (patrón de referencia), pues un valor por encima de 2 se considera proteína de alta calidad y uno por debajo de 1.5 se considera de baja calidad (Zengin et al., 2012); además, los valores de este estudio fueron superiores a los hallados por Gutiérrez et al. (2008) para la variedad QPM V-537 cuyo valor de PER fue de 2.47 .

Valor biológico (VB) estimado de la proteína. La conversión de las variedades a QPM indujo un cambio positivo en cuanto a este parámetro, duplicando su valor. Las variedades predecesoras resultaron ser estadísticamente iguales entre sí, pero con valores menores respecto de las variedades híbridas, pues se encontró un aumento del VB en los maíces híbridos, pasando de $37.56 \%$ a $78.63 \%$ en la variedad Chichén Itzá y en Sac Beh de $39.15 \%$ a $86.55 \%$, al darse la conversión a QPM. Este comportamiento fue el esperado ya que reportes como los de Upadyay et al. (2000); Tang et al. (2013) e Ignjatovic et al. (2015), indican que al convertir una variedad de maíz normal a QPM, aumenta su valor biológico aproximadamente de $45 \%$ a $80 \%$, comportamiento similar observado para estas variedades. Podría atribuirse que el cambio observado en las variedades de estudio en el VB se debe a la redistribución de la proporción de aminoácidos esenciales que se observó en la tabla 5, principalmente por mayor cantidad de Lis y Trp en Chichén Itzá y mayor cantidad de aminoácido aromáticos, Lis y Trp en Sac Béh dando evidencia que junto con la incorporación del gen opaco-2 se dieron efectos positivos en la calidad de la proteína.

Tabla 5. Cómputo químico y su relación con aminoácidos esenciales de las variedades de maíz híbrido y predecesor.

Table 5. Chemical score and its relation to essential amino acids in native and hybrid maize varieties.

\begin{tabular}{|c|c|c|c|c|c|}
\hline $\begin{array}{l}\text { Aminoácido (g AA/ } \\
100 \mathrm{~g} \text { de proteína) }\end{array}$ & $\begin{array}{c}\text { Niños } 0.5 \text { - } 3 \\
\text { años* }\end{array}$ & $\begin{array}{c}\text { Predecesor } \\
\text { Chichén Itzá CQ (\%) }\end{array}$ & $\begin{array}{c}\text { Predecesor } \\
\text { Sac Béh CQ (\%) }\end{array}$ & $\begin{array}{l}\text { Híbrido Chichén } \\
\text { Itzá CQ (\%) }\end{array}$ & $\begin{array}{c}\text { Híbrido Sac Béh } \\
\text { CQ (\%) }\end{array}$ \\
\hline Histidina & 2.0 & $86.00 \pm 4.50^{\mathrm{b}}$ & $100.00 \pm 0.00^{\mathrm{a}}$ & $100.00 \pm 0.00^{\mathrm{a}}$ & $100.00 \pm 0.00^{\mathrm{a}}$ \\
\hline Isoleucina & 3.2 & $11.25 \pm 0.31^{\mathrm{b}}$ & $7.81 \pm 1.53^{c}$ & $93.14 \pm 9.99^{\mathrm{a}}$ & $83.53 \pm 7.16^{\mathrm{a}}$ \\
\hline Leucina & 6.6 & $100.00 \pm 0.00^{\mathrm{a}}$ & $100.00 \pm 0.00^{\mathrm{a}}$ & $100.00 \pm 0.00^{\mathrm{a}}$ & $100.00 \pm 0.00^{\mathrm{a}}$ \\
\hline Lisina & 5.7 & $24.21 \pm 1.91^{b}$ & $26.14 \pm 0.28^{b}$ & $44.56 \pm 2.7^{a}$ & $47.72 \pm 2.44^{\mathrm{a}}$ \\
\hline SAA & 2.7 & $100.00 \pm 0.00^{\mathrm{a}}$ & $100.00 \pm 0.00^{\mathrm{a}}$ & $100.00 \pm 0.00^{\mathrm{a}}$ & $100.00 \pm 0.00^{\mathrm{a}}$ \\
\hline AAA & 5.2 & $100.00 \pm 0.00^{\mathrm{a}}$ & $95.00 \pm 4.52^{\mathrm{b}}$ & $100.00 \pm 0.00^{\mathrm{a}}$ & $100.00 \pm 0.00^{\mathrm{a}}$ \\
\hline Treonina & 3.1 & $100.00 \pm 0.00^{\mathrm{a}}$ & $100.00 \pm 0.00^{\mathrm{a}}$ & $100.00 \pm 0.00^{\mathrm{a}}$ & $100.00 \pm 0.00^{\mathrm{a}}$ \\
\hline Triptófano & 0.85 & $3.53 \pm 0.71^{c}$ & $3.53 \pm 0.24^{c}$ & $29.41 \pm 0.47^{b}$ & $41.18 \pm 0.71^{\mathrm{a}}$ \\
\hline Valina & 4.3 & $51.63 \pm 3.81^{\mathrm{b}}$ & $100.00 \pm 0.00^{\mathrm{a}}$ & $36.51 \pm 5.25^{c}$ & $30.93 \pm 1.21^{c}$ \\
\hline
\end{tabular}

$\mathrm{AA}=\mathrm{Aminoácido,} \mathrm{CQ}=$ Cómputo químico, $\mathrm{SAA}=\mathrm{Aminoácidos} \mathrm{azufrados,} \mathrm{AAA}=\mathrm{Aminoácidos}$ aromáticos. *Patrón FAO/ONU/WHO 2007. a-c Letras diferentes dentro de la misma fila indican diferencia significativa. Los valores son promedios \pm desviación estándar. 


\section{CONCLUSIONES}

La incorporación del gen opaco-2 tuvo efectos sobre las características químicas y nutrimentales de las variedades de maíz híbrido Sac Béh y Chichén Itzá desarrollados en la Península de Yucatán en México. Se incrementó la cantidad de proteína y en mayor medida el contenido de aceite hasta cerca de $7 \%$, para ser considerados como "High-Oil Corn". Los minerales mayoritarios fueron fósforo, potasio y magnesio, y el contenido de éstos no presentó diferencias apreciables en las variedades mejoradas. El aceite de las variedades híbridas es de buena calidad por su alto contenido de ácidos grasos mono-insaturados y ácidos grasos poli-insaturados y tuvieron mayor contenido de ácido oleico y menor de ácido palmítico, posiblemente por la incorporación del gen opaco-2.

El mejoramiento tuvo un efecto positivo en el perfil de aminoácidos con mayores niveles de aminoácidos esenciales como lisina, triptófano, fenilalanina e isoleucina. Los maíces híbridos poseen una calidad de proteína superior a las variedades predecesoras por su mayor contenido de aminoácidos esenciales que cubren mejor el patrón de referencia, mayor digestibilidad, valores de puntaje de aminoácidos corregido con digestibilidad de proteínas nueve veces mayores y un valor biológico estimado del doble. Conjuntamente los valores de relación de eficiencia proteica calculada indicaron que son proteínas de buena calidad. En el presente trabajo se demostró que las variedades híbridas Sac beh y Chichén Itzá presentan características químicas y nutrimentales que la clasifican como variedades de alta calidad de proteína y alto contenido de aceite, que indican mejoras en el valor nutricional de las variedades nativas con la incorporación del gen opaco-2. Por lo tanto, éstas demuestran potencial para ser consumidas y con ello, poder contribuir a disminuir la tasa de desnutrición infantil en el Sureste de México.

\section{AGRADECIMIENTOS}

Loa autores agradecen al Instituto Nacional de Investigaciones Forestales Agrícolas y Pecuarias (INIFAP) por haber proporcionado de las muestras de granos de maíz nativo y QPM para la realización de la investigación.

\section{REFERENCIAS}

Aguilar-Castillo, G., Gómex-Montiel, N., Torres-Pimentel, H. y Vázquez-Carrillo. G. 2010. Sac-Beh y Chichen Itzá: variedades de maíz de calidad proteínica para el sistema RozaTumba-Quema de la península de Yucatán. Instituto Nacional de investigaciones Forestales y Pecuarias. Centro de Investigación regional del sureste. Campo Experimental Mocochá. Folleto técnico 3: 5-8

Akalu, G., Taffesse, S., Gunaratna, N.S. y De Groote, H. 2010. The effectiveness of quality protein maize in improving the nutritional status of young children in the Ethiopian highlands. Food and Nutrition Bulletin. 31: 418-430.

Alaíz, M., Navarro, J. L., Girón, J. y Vioque E. 1992. Amino acid analysis by high-performance liquid chromatography after derivatization with diethyl ethoxymethylenemalonate. Journal of Chromatography. 591: 181-186.
AOAC. 2012. Oficial methods of analysis of AOAC International., editor Latimer G.W., 19th. Edition, USA.

Bódi, Z., Pepó, P., Kovács, A., Széles, E. y Györi, Z. 2008. Macroand microelement contents of blue and red kernel corns, Cereal Research Communications. 36: 147-155.

Cázares, E., Chávez, J. L., Salinas, Y., Casillo, F. y Ramírez, P. 2015. Variación en la composición del grano entre poblaciones de maíz (Zea mays L.) nativas de Yucatán, México. Agrociencia. 49: 15-30.

Cuevas, E.O., Verdugo, N.M., Ângulo, P.I., Milán, J., Mora, R., Bello, L. A., Garzón, J.A. y Reyes, C. 2006. Nutritional properties of tempeh flour from quality protein maize (Zea mays L.). LWT Food Science and Technology. 39: 1072-1079.

FAO Y FINUT. 2017. Organización de la Naciones Unidas para la Alimentación y la Agricultura (FAO) y la Fundación Iberoamericana de Nutrición (FINUT) Granada, España, 2017 Evaluación de la calidad de las proteínas de la dieta en nutrición humana Consulta de expertos. 31 de Marzo-2 de Abril, 2011 Auckland, Nueva Zelanda. FAO ISSN 1014-2916 ISBN 978-84-697-74731.

Friedman, M. 1996. Nutritional Value of Proteins from Different Food Sources. Journal Agriculture and Food Chemistry. 44: 6-29.

Gayral, M., Gaillard, C., Bakan, B., Dalgalarrondo, M., Elmorjani, K., Delluc, C., Brunet, S., Linossier, L., Morel, M.H. y Marion, D. 2016. Transition from vitreous to floury endosperm in maize (Zea mays L.) kernels is related to protein and starch gradients. Journal of Cereal Science, 68:148-154.

Gutiérrez, R., Ayala, A. E., Milán, J., Garzón, J. A., López, J.A. y Reyes C. 2008. Technological and nutritional properties of flours and tortillas from nixtamalized and extruded quality protein maize (Zea mays L.). Cereal Chemistry. 85: 808-816.

Gutiérrez, M.L., Coronado, E., Vázquez, F. A., López, Y. L. y Ortega, A. 2009. Caracterización física y química de maíz de calidad proteínica mejorada, Physical and chemical characterization of quality protein maize. CyTA - Journal of Food. 7: 111-118.

Gwirtz, J.A. y García M.N. 2014. Processing maize flour and corn meal food products, Annals of the New York Academy of Sciences. 1312: 66-75.

Hasjim, J., Srichuwong, S., Scott, M.P. y Jane J.L. 2009. Kernel composition, starch structure, and enzyme digestibility of opaque-2 maize and quality protein maize, Journal of Agricultural and Food Chemistry. 57: 2049-2055.

Hsu, H.W., Vavar, D.L., Satterlee, L.D. y Miller, G.A. 1977. A multienzyme technique for estimating protein digestibility, Journal of food science. 42: 1269-1273.

Ignjatovic, D., Vancetovic, J., Trbovic, D., Dumanovic, Z., Kostadinovic, M. y Bozinovic, S. 2015. Grain nutrient composition of maize (Zea mays L.) drought-tolerant populations, Journal of Agricultural and Food Chemistry. 63: 1251-1260.

Kriz, A. L. 2009. Enhancement of amino acid availability in corn grain. En: Molecular genetic approaches to maize improvement. Biotechnology in agriculture and forestry. Kriz A.L., Larkins B.A. (eds), pp. 79-89, Springer, Berlin.

Lee, Y.B., Elliot, J.G., Rickansrud, D. A. y Hagberg E.C. 1978. Predicting protein efficiency ratio by the chemical determination of connective tissue content in meat. Journal of Food Science. 43: 1359-1362.

Li, J.S. y Vassal, S. K. 2016. Maize: Quality protein maize. En: Encyclopedia of Food Grains (Second Edition), Vol. 4, pp. 420-424., Elsevier, China. 
Martínez, M., Ortiz, R. y Raigón, M.D. 2017. Contenido de fósforo, potasio, zinc, hierro, sodio, calcio y magnesio, análisis de su variabilidad en accesiones cubanas de maíz, Cultivos Tropicales. 38: 92-101.

Mendoza, M., Andrio, E., Juárez, J. M., Mosqueda, C., Latournerie, L., Castañón, G., López, A. y Moreno, E. 2006. Contenido de lisina y triptófano en genotipos de maíz de alta Calidad proteica y normal. Universidad y Ciencia. 22: 153-161.

Menkir, A. 2008. Genetic variation for grain mineral content in tropical-adapted maize inbred lines, Food Chemistry. 110: 454-464.

Mohammad, S., Dikshit, N., Sekhar, C., Kumar, P. y Kumar S. 2018. Biochemical evaluation of dent corn (Zea mays L.) genotypes cultivated under rainfed conditions in the hills of north western Indian Himalayan state of Jammu and Kashmir. Journal of Applied and Natural Science. 10: 196-201.

Montgomery, D.C. 2008. Diseño y análisis de experimentos. 2a ed., pp. 100-102, editorial Limusa -Wiley, México.

Morup, I. K. y Olesen, E. S. 1976. New method for prediction of protein value from essential amino acid pattern. Nutritional Report International. 13: 355-365.

Norma Mexicana NMX-FF-034/1-SCFI-2002. Productos alimenticios no industrializados para consumo humano - Cereales - Parte I: Maíz blanco para proceso alcalino para tortillas de maíz y productos de maíz nixtamalizadoEspecificaciones y métodos de prueba.

Preciado, R.E., Vázquez, M.G., Figueroa, J.D., Guzmán, S.H., Santiago, D. y Topete, A. 2018. Fatty acids and starch properties of high-oil maize hybrids during nixtamalization and tortilla-making process, Journal of Cereal Science. 83: 171-179.

Salazar, L. L. y Magaña, M. Á. 2016. Aportación de la milpa y traspatio a la autosuficiencia alimentaria en comunidades mayas de Yucatán; Estudios sociales. 24-25: 182-203.

Sanjeev, P., Chaudhary, D. P., Sreevastava, P., Saha, S., Rajenderan, A., Sekhar J. C. y Chikkappa, G. K. 2014. Comparison of Fatty Acid Profile of Specialty Maize to Normal Maize, Journal of the American Oil Chemists' Society. 91: 1001-1005.
Schaarfsma, G. 2005. The Protein Digestibility-Corrected Amino Acid Score (PDCAAS)-AConcept for describing protein quality in foods and food ingredients: A critical review. Journal of AOAC International. 88: 988-994.

Shewry, P.R. 2007. Improving the protein content and composition of cereal grain. Journal of Cereal Science. 46: 239-250.

Singh, N., Vasudev, S., Yadava, D.K., Chaudhary, D.P. y Prabhu, K.V. 2013. Oil improvement in maize: Potential and prospects. En: Maize: Nutrition Dynamics and Novel Uses. Chaudhary D., Kumar S., Langyan S. (eds), p. 79, Springer, New Delhi.

Tang, M., He, X., Luo, Y., Ma, L., Tang, X. y Huang, K. 2013. Nutritional assessment of transgenic lysine-rich maize compared with conventional quality protein maize. Journal of the Science of Food and Agriculture. 13: 1049-1054.

Tiwari, M.R., Chapagain, B.P., Shah, M.K. y Shrestha, Y.K. 2013. Evaluation of quality protein maize for growth performance of crossbred piglets in western hills of nepal. Global Journal of Science Frontier Research Agriculture and Veterinary. 13: $1-6$.

Upadyay, S.R., Gurug, D. B., Paudel, D. C., Koirala, K. B., Sah, S. N., Prasad, R. C., Pokhrel, B. B. y Dhakal, R. 2009. Evaluation of quality protein maize (QPM) genotypes under rainfed mid hill environments of nepal. Nepal Journal of Science and Technology 10: 9-14.

Val, L.D., Schwartz, S.H., Kerns, M.R. y Deikman, J. 2009. Development of a high oil trait for maize. En: Molecular genetic approaches to maize improvement. biotechnology in agriculture and forestry, Kriz A.L., Larkins B.A. (eds), Vol. 63, p. 603, Springer, Berlin.

Yust, M., Pedroche, J., Girón, J., Vioque, E., Millán, F. y Alaíz, M. 2004. Determination of tryptophan by high-performance liquid chromatography of alkaline hydrolysates with spectrophotometric detection, Food Chemistry. 85: 317-320.

Zengin, G., Aktumsek, A., Guler, G. O., Cakmak, Y. S., Girón, J., Alaíz, M. y Vioque, J. 2012. Nutritional quality of protein in the leaves of eleven Asphodeline species (Liliaceae) from Turkey. Food Chemistry. 135: 1360-1364. 